\title{
Toxoplasmose sistêmica associada à forma ocular bilateral atípica mimetizando necrose retiniana aguda
}

\author{
Systemic toxoplasmosis associated to the atypical bilateral \\ ocular involvement mimicking acute retinal necrosis

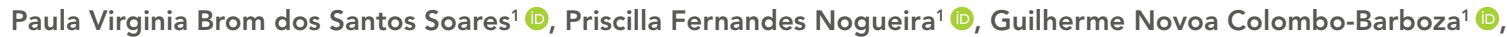 \\ Marcello Novoa Colombo-Barboza' ${ }^{1}$, Marta Fabiane Gouvêa Barioni' ${ }^{1}$ (])
}

Descritores:

Síndrome de necrose retiniana aguda; Toxoplasmose;

Mononucleose infecciosa; Uveíte; Tomografia de coerência óptica; Diagnóstico diferencial

Keywords:

Retinal necrosis syndrome, acute; Toxoplasmosis; Infectious mononucleosis; Uveitis; Tomography, optical coherence; Diagnosis, differential

Recebido: 22-04-2021

Aceito: 10/9/2021

Autor correspondente: Paula Virginia Brom dos Santos Soares Endereço completo: Avenida Conselheiro Nébias 355, Santos, SP, Brasil. Tel.: (16) 99700-7083

E-mail: paulavbrom@hotmail.com

Instituição de realização do trabalho: Hospital Oftalmológico Visão Laser, Santos, SP, Brasil.

Fonte de auxílio à pesquisa: não financiado.

Conflitos de interesse: os autores declaram que não há conflitos de interesses.

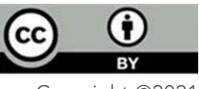

Copyright (C2021

\section{RESUMO}

A toxoplasmose ocular pode se manifestar de forma atípica, rara, bilateral e associada à necrose retiniana aguda. É apresentada em pacientes imunossuprimidos, resultando em grave perda visual, se não for solucionada rapidamente. Relata-se um caso atípico de toxoplasmose ocular em paciente diabético, que, em sua internação prévia, já evidenciava aspecto sistêmico, o qual foi elucidado pelo exame clínico oftalmológico e pela anamnese. Além disso, a rotina do setor de uveítes, ao solicitar as sorologias de forma direcionada e criteriosa, foi imprescindível para o diagnóstico da toxoplasmose sistêmica associado à lesão ocular atípica bilateral, mimetizando necrose retiniana aguda com desfecho favorável.

\section{ABSTRACT}

Ocular toxoplasmosis can present with an atypical, rare, bilateral involvement, and associated with acute retinal necrosis. It occurs in immunosuppressed patients, resulting in severe visual loss, if not quickly solved. We report an atypical case of ocular toxoplasmosis in a diabetic patient, who already showed a systemic aspect in a previous hospitalization, which was elucidated by the ophthalmologic examination and history. In addition, the routine of the uveitis sector requesting serology in a directed and carefu way was essential for the diagnosis of systemic toxoplasmosis associated with atypical bilateral ocular lesion, mimicking acute retinal necrosis with good outcome. 


\section{INTRODUÇÃO}

A toxoplasmose é uma patologia causada por Toxoplasma gondii, que afeta até um terço da população mundial. ${ }^{(1)}$ No Brasil, a soroprevalência varia de 50\% a 80\%. ${ }^{(2)}$ Cerca de 70\% dos casos são assintomáticos ou subclínicos. ${ }^{(3)}$

A mais típica manifestação clínica é a forma ganglionar, caracterizada por linfadenopatia indolor, cervical ou occipital, cefaleia, dor de garganta, febre, mal-estar, sudorese noturna, mialgia e exantema. Menos frequentemente, miocardite, pneumonite, polimiosite, encefalite e hepatite podem comprometer até mesmo indivíduos imunocompetentes. ${ }^{(3)}$

O diagnóstico diferencial se faz com necrose retiniana aguda (NRA), linfomas, mononucleose infecciosa, doença da arranhadura do gato, sarcoidose, tuberculose, carcinoma metastático e leucemia. ${ }^{(3)}$

A toxoplasmose ocular é responsável por 50\% dos casos de uveítes no Brasil. ${ }^{(4)}$ É a forma mais comum de uveíte posterior infecciosa, podendo ser recidivante e provocar severas sequelas, incluindo a cegueira, devendo ser sempre investigada. A lesão típica é a retinocoroidite granulomatosa focal necrosante, e apresenta característica unilateral e, frequentemente, com cicatriz retinocoroidal adjacente e inflamação vítrea. Além disso, suas lesões podem ser únicas, múltiplas ou satélites à cicatriz retiniana. ${ }^{(1,5,6)}$

A toxoplasmose ocular apresenta diversas formas atípicas. São apresentações menos comuns, mas mais agressivas, caracterizadas por lesões grandes, multifocais e/ou bilaterais, podendo mimetizar NRA, postergando o diagnóstico precoce. Essas formas atípicas são mais prevalentes em pacientes imunossuprimidos, como idosos e diabéticos..$^{(5-7)}$

A NRA é uma patologia inflamatória rapidamente progressiva, que compromete gravemente a visão, se não diagnosticada. É caracterizada por áreas focais e bem demarcadas de necrose retiniana na periferia, além de vasculopatia oclusiva, vitreíte e reação de câmara anterior. ${ }^{(8)}$ O diagnóstico é clínico. Entretanto, os achados podem ser atípicos, dificultando o diagnóstico. ${ }^{(9)}$

O objetivo deste estudo foi relatar um caso atípico de toxoplasmose ocular com aspecto de NRA em paciente diabético, que, em sua internação prévia, já evidenciava aspecto sistêmico da doença.

Este trabalho foi aprovado pelo Comitê de Ética em Pesquisa da Universidade Metropolitana de Santos, parecer \# 4623811, CAAE: 40862020.5.0000.5509.

\section{RELATO DO CASO}

Paciente do sexo masculino, 39 anos, negro, auxiliar de edificação, encaminhado com queixa de mancha preta em olho esquerdo (OE) há 30 dias. Referia hipertensão arterial sistêmica, diabetes e internação recente com diagnóstico de mononucleose infecciosa com encefalite, relatando, na época, febre, sudorese noturna, mialgia, gânglios cervicais aumentados, cefaleia, náuseas, vômitos e perda de $26 \mathrm{~kg}$ desde a internação até a consulta oftalmológica.

Ao exame oftalmológico, apresentava acuidade visual com correção de 20/20 em olho direito (OD) e 20/25 em OE, segundo a tabela de Snellen, e pressão intraocular (PIO) de 19mmHg em OD e 40mmHg em OE. A biomicroscopia revelou, no OD, raros precipitados ceráticos (PKs keratic precipitates) finos e células vítreas 1+/4+ e, no OE, PKs finos difusos, células em câmara anterior $1+/ 4+e$ células vítreas $3+/ 4+$. A fundoscopia por meio do mapeamento de retina e angiofluoresceinografia apresentou-se normal no OD; no OE indicou a presença de retinite extensa, semelhante à necrose retiniana perivascular, com vasculite atingindo principalmente vênulas em periferia, associada à oclusão arterial em média periferia temporal (Figura 1).

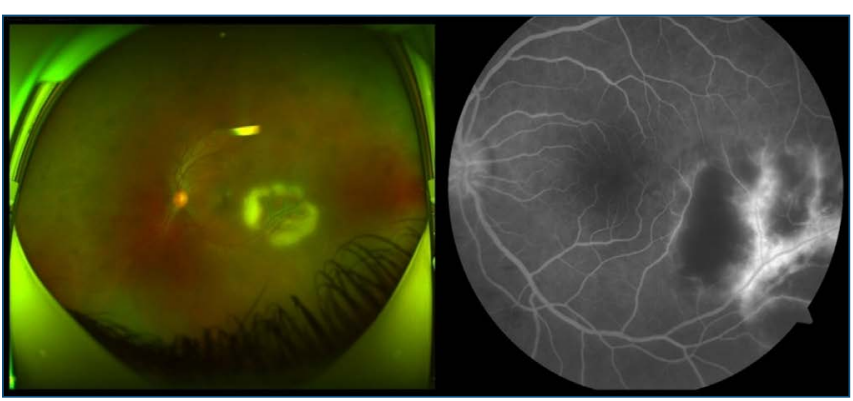

Figura 1. Optomap e angiofluoresceinografia evidenciando lesão inicial em olho esquerdo.

Devido à internação prévia, com perda de peso e diabetes associados a sinais inflamatórios bilaterais, mesmo sem queixa em OD, foi realizada hipótese de NRA, sendo solicitados exames laboratoriais e prescritos aciclovir oral $4 \mathrm{~g}$ ao dia, acetato de prednisolona 1\%, e associação de brinzolamida com maleato de timolol em OE.

Após 3 dias, retornou com exames laboratoriais solicitados, referindo que, para realizar o teste tuberculínico no posto de saúde, foi avaliado pelo infectologista, que prescreveu sulfametoxazol 8oomg e trimetoprima 16omg após verificar imunoglobulina $\mathrm{M}$ (IgM) e G (IgG) de toxoplasmose reagentes e demais sorologias negativas. Apresentava acuidade visual com correção de 20/20, em OD, e 20/30, em OE, e biomicroscopia no OD, com presença de células vítreas 1+/4+; no OE, exibia PKs finos, traços de células de câmara anterior e células vítreas 3+/4+. A 
PIO era de $13 \mathrm{mmHg}$ em OD e $14 \mathrm{mmHg}$ em OE, com mapeamento de retina sem alteração em ambos os olhos, diminuição da extensão da lesão retiniana e melhora da vasculite.

O exame de tomografia de coerência óptica (OCT - optical coherence tomography) foi realizado após 26 dias de tratamento, já demonstrando lesão em processo de cicatrização e formação de discreta membrana epirretiniana macular em OE.

Após 1 mês, relatava melhora, e o exame de fundoscopia sob midríase revelou a presença de lesão retiniana em cicatrização em extrema periferia da região temporal inferior em OD e regressão importante da lesão em média periferia temporal do OE (Figura 2). Com a hipótese de toxoplasmose sistêmica aguda com forma ocular atípica bilateral, foi mantido o tratamento sistêmico com sulfametoxazol 80omg e trimetoprima 16omg, apresentando melhora da visão e cicatrização das lesões na retina em ambos os olhos.

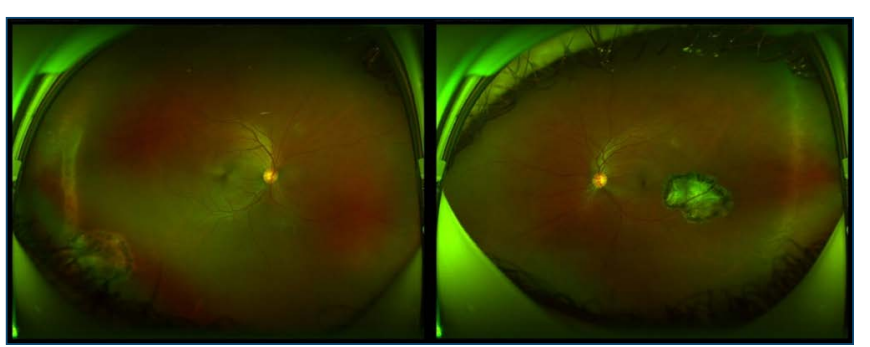

Figura 2. Optomap evidenciando lesões cicatrizadas em ambos os olhos após 1 mês de tratamento.

\section{DISCUSSÃO}

A toxoplasmose ocular atípica pode ser identificada em situações de imunossupressão, e a literatura relata retardo na elucidação desses casos. ${ }^{(6)}$ A retinite da toxoplasmose atípica continua sendo o principal diagnóstico diferencial de NRA, com ambas apresentando um prognóstico ruim, devendo ser abordadas rapidamente. ${ }^{(4)}$

O diagnóstico de toxoplasmose e NRA em pacientes imunodeprimidos deve ser cauteloso, devido à grande chance de mimetização. Casos de toxoplasmose atípica simulando NRA são de difícil esclarecimento e retardam o diagnóstico, devendo ser aventada essa hipótese, caso o paciente não responnda adequadamente à terapia antiviral. ${ }^{(6)}$

A toxoplasmose ocular apresenta-se como uma retinite unilateral, geralmente adjacente a uma cicatriz de retinocoroidite prévia e associada à inflamação vítrea. Em imunocomprometidos, idosos e em alguns casos de infecção aguda recentemente adquirida, ela se torna agressiva, apresentando lesões necrosantes extensas, multifocais e, às vezes, bilaterais, dificultando o diagnóstico diferencial com NRA. ${ }^{(10)}$

Na investigação diagnóstica, não há consenso se a amostra mais sensível para a detecção do toxoplasma é através do humor aquoso ou do vítreo, mas a paracentese vítrea é mais cara e mais invasiva - porém mais fácil de ter complicações. ${ }^{\left({ }^{10}\right)}$ Assim, a análise da reação em cadeia da polimerase (PCR) do humor aquoso que detecta o agente infeccioso auxilia no diagnóstico correto. (9) Em pacientes imunocomprometidos, que têm redução da resposta de autoanticorpo, a PCR é mais sensível para o diagnóstico patogênico. ${ }^{(11)}$ Um estudo comparou três métodos (imunoblot/western blot, cálculo do coeficiente de Goldmann-Witmer e PCR) biológicos para o diagnóstico de toxoplasmose ocular no humor aquoso e nas amostras séricas. Evidenciou-se que a combinação deles aumentou a sensibilidade diagnóstica para 97\%. É importante ressaltar que a avaliação histopatológica por meio da biópsia coriorretiniana é benéfica para a confirmação do diagnóstico. ${ }^{(12,13)}$

A OCT é útil para diferenciar as causas de retinite necrosante e indicar se a infecção é aguda ou se está evoluindo para cicatrização quiescente. ${ }^{(14)}$ Os sinais da OCT na toxoplasmose exibem depósitos hialoides ovais hiperrefletivos no vítreo, que se tornam menores e entram na retina, desaparecendo com o tempo, sem deixar cicatriz. A retinocoroidite toxoplasmática aparece nas imagens como uma área de retina hiperrefletiva espessa e homogeneamente rompida, com a coroide exibindo áreas focais espessas e perda de sua arquitetura, tornando-se homogeneamente hiporrefletiva. ${ }^{(15)}$ A NRA caracteriza-se por depósitos hialoides ovais hiperrefletivos no vítreo, além de, na fase aguda, manifestar áreas hiperrefletivas na retina e desorganização estrutural retiniana, e, na fase tardia, revelar afinamento da retina, com área hiperrefletiva, que corresponde à perda de tecido retiniano e à formação de cicatriz. ${ }^{(8,15)}$

A apresentação de toxoplasmose ocular bilateral é rara, como no caso exposto, em que o paciente diabético com internação recente e diagnóstico inicial de mononucleose evoluiu após 1 mês com a forma atípica de toxoplasmose ocular bilateral de aspecto semelhante à NRA. Com isso, evidencia-se a importância da anamnese e do exame oftalmológico criterioso, assim como o conhecimento da história natural da patologia para o diagnóstico. Além disso, a rotina do setor de uveítes, ao solicitar as sorologias de forma direcionada, também foi imprescindível para a elucidação precoce do caso, evoluindo com desfecho favorável. 


\section{REFERÊNCIAS}

1. Montoya JG, Liesenfeld O. Toxoplasmosis. Lancet. 2004;363(9425):1965-76.

2. Kompalic-Cristo A, Britto C, Fernandes O. Diagnóstico molecular da toxoplasmose: revisão. J Bras Patol Med Lab. 2005;41(4):229-35.

3. Oréfice F, Cunha Filho R, Barboza AL, Oréfice JL, Calucci D. Toxoplasmose ocular adquirida: toxoplasmose ocular pós-natal. Rev Bras Oftalmol. 2010;69(3):184-207.

4. Morais FB, Arantes TE, Muccioli C, Allemann N. Ultrasonographic characteristics of active ocular toxoplasmosis. Arq Bras Oftalmol. 2019;82(4):317-21.

5. Oréfice F. Uveíte clínica cirúrgica: texto \& atlas. 2a ed. Rio de Janeiro: Cultura Médica; 2005.

6. Commodaro AG, Belfort RN, Rizzo LV, Muccioli C, Silveira C, Burnier MN Jr, et al. Ocular toxoplasmosis: an update and review of the literature. Mem Inst Oswaldo Cruz. 2009;104(2):345-50.

7. Smith JR, Cunningham ET Jr. Atypical presentations of ocular toxoplasmosis. Curr Opin Ophthalmol. 2002;13(6):387-92.

8. Suzuki J, Goto H, Minoda H, Iwasaki T, Sakai J, Usui M. Analysis of retinal findings of acute retinal necrosis using optical coherence tomography. Ocul Immunol Inflamm. 2006;14(3):165-70.

9. Balansard B, Bodaghi B, Cassoux N, Fardeau C, Romand S, Rozenberg $F$, et al. Necrotising retinopathies simulating acute retinal necrosis syndrome. Br J Ophthalmol. 2005;89(1):96-101.

10. Fine HF, Burke SP, Albini TA. Toxoplasmosis retinitis masquerading as acute retinal necrosis. Ophthalmic Surg Lasers Imaging Retina. 2016;47(10):8959.

11. Crosson JN, Kuthyar S, Shantha JG, Debiec MR, Laird PW, Hwang CS, et al. Toxoplasmosis chorioretinitis mimicking acute retinal necrosis associated with local corticosteroid. Int J Retina Vitreous. 2020;6:21.

12. Commodaro AG, Belfort RN, Rizzo LV, Muccioli C, Silveira C, Burnier MN Jr, et al. Ocular toxoplasmosis: an update and review of the literature. Mem Inst Oswaldo Cruz. 2009;104(2):345-50.

13. Balayre S, Gomez K, Tribut A, Dore P, Gobert F. Toxoplasma gondii and necrotizing retinitis: a case report. J Fr Ophtalmol. 2003;26(8):837-41. French.

14. Alwassia AA, Cho H, Adhi M, Duker JS, Baumal CR. Sequential optical coherence tomography images of retinal necrosis in acute ocular toxoplasmosis. Retin Cases Brief Rep. 2013;7(1):98-101

15. Pichi F, Invernizzi A, Tucker WR, Munk MR. Optical coherence tomography diagnostic signs in posterior uveitis. Prog Retin Eye Res. 2020;75:100797. 